\title{
Construction of Complete (k,n)-arcs from Conics in PG(2,13)
}

\author{
Shua'a M. Aziz \\ Department of Mathematics, \\ College of Computer and Mathematics Science \\ University of Mosul, Iraq \\ e-mail:shuaamaziz@gmail.com
}

Received on: $23 / 12 / 2013$

Accepted on: 9/4/2014

\begin{abstract}
This research contains the construction of complete $(\mathrm{k}, \mathrm{n})$-arcs using geometric method and putting a condition that each constructed arc must begin with reference unit four points ,then constructing all conics that each one contains the fundamental four points ,and then make union operation between each two conics and compute all the points need to be deleted (or added) to get complete (k,n)-arcs each time for $2 \leq n \leq 12$. This research is a construction procedure not a classification method .
\end{abstract}

keywords: Complete arc, $(k, n)$-arc, conic ,PG(2,13) .

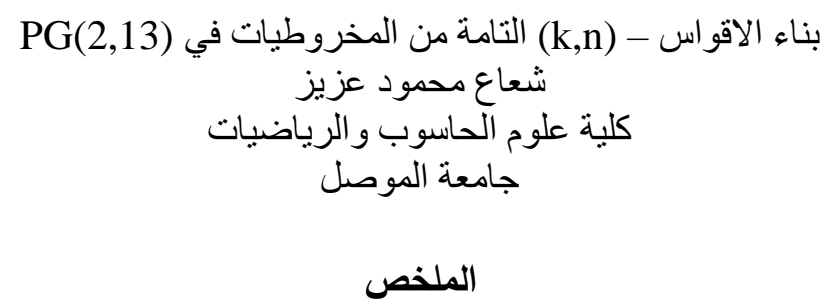

تاريخ القبول : 9/4/2014

تاريخ الاستلام : 23/12/2013

تضمن هذا البحث بناء الاقواس - (k,n) التامة باستخدام الطريقة الهندسية مبتدئين ومشترطين ان يبتديء

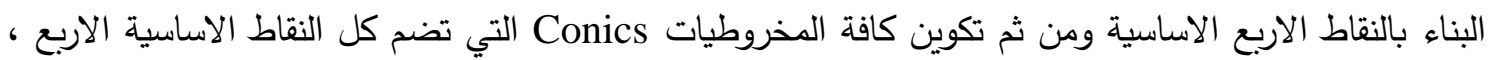

يلي ذلك اجراء عملية الاتحاد بين كل اثثين منهم واحتساب النقاط المطلوب حذفها (أو إضافتها) في كل حالة وذلك

للوصول الى الاقواس-(k,n) التامة ولقيم 12 n s 2 ـ ـ إن هذا البحث هو وسيلة للبناء وليس طريقة للتصنيف.

الكلمات المفتاحية : الاقواس التامة، الاقواس - (k,n)) ، الاقواس المخروطية (2,13) •

\section{Introduction}

Finding the exact value of $\mathrm{k}$ where $(\mathrm{k}, \mathrm{n})$-arc exists, is a big problem, researchers try to fix an $\mathrm{n}$ to get run on $\mathrm{k}$ and others try to fix $\mathrm{k}$ also fix $\mathrm{n}$ to check whether the $(\mathrm{k}, \mathrm{n})$-arc exist or not, see for example, [6],[2] and[5], some researchers try to use new algorithms to get exact results, but does not meet the general goal, because these algorithms are trying to check and build little number of the huge number of these $(\mathrm{k}, \mathrm{n})$ arcs, see for example [3], [11] and [12].

Researching in this problem; driving man to think in different ways ,the famous direction is classifying the (k,n)-arcs into classes according to $n$, and trying to study the groups, spectrum (the number of $\mathrm{i}$-secant lines $\tau_{i}, i=0, \ldots, n$ in the plane [4]), point types, and other properties analytically or computationally according to the way that each class had derived, see for example, [13]. Another way for fighting this problem is 
to split the problem into small pieces and study each piece lonely, this idea is needed when the plane is large and the splitting is beneficial, so constructing the piece is so important like the study on this piece, may this piece be a cubic as in [13] or to be a conic as in [9] and[10].

This research is to construct the $(\mathrm{k}, \mathrm{n})$-arcs that are arising from conics and each one of them containing the fundamental arc.

\section{Preliminaries}

\subsection{Definition [7]}

Let $\mathrm{V}$ be an $(\mathrm{n}+1)$-dimensional vector space over the field $\mathrm{K}$ with origin 0 , then consider the equivalence relation on the points of $\mathrm{V} \backslash\{0\}$ whose equivalence classes are the one-dimensional subspaces of $\mathrm{V}$ with the origin deleted ; that is ,if $x, y \in V \backslash\{0\}$ and for some basis $\mathrm{x}=\left(x_{0}, \ldots, x_{n}\right), \mathrm{y}=\left(y_{0}, \ldots, y_{n}\right), \mathrm{x}$ is equivalent to $\mathrm{y}$ if ,for some $\mathrm{t}$ in the field $\mathrm{K}$ without the origin 0 , we have $y_{i}=t x_{i}$ for all $\mathrm{i}$. Then, the set of equivalence classes is the $n$-dimensional projective space over $K$ and is denoted by $P G(n, K)$ or, if $\mathrm{K}=\mathrm{GF}(\mathrm{q})$, by $\mathrm{PG}(\mathrm{n}, \mathrm{q})$.

In this paper set $n=2, K=G F(13)$, and we get the finite projective plane $P G(2,13)$.

\subsection{Definition [7]}

$A(k, n)-\operatorname{arc} A$ in $P G(2, q)$ is a set of $k$ points such that some line of the plane meets $\mathrm{A}$ in $\mathrm{n}$ points, but such that no line meets $\mathrm{A}$ in more than $\mathrm{n}$ points, where $n \geq 2$. A (k,n)arc is complete if there is no $(\mathrm{k}+1, \mathrm{n})$-arc containing it.

\subsection{Definition [7]}

Let $\mathrm{K}\left[x_{0}, \ldots, x_{n}\right]$ be the polynomial ring in $x_{0}, \ldots, x_{n}$ variables over the field $\mathrm{K}$, if $\mathrm{f}$ in $\mathrm{K}\left[x_{0}, \ldots, x_{n}\right]$ be homogeneous; it is called a form. Let $\mathrm{x}=\left(x_{0}, \ldots, x_{n}\right)$, then $\mathrm{f}(\mathrm{x})=\mathrm{f}\left(x_{0}, \ldots, x_{n}\right)$. A subset $\mathrm{F}$ of $\mathrm{PG}(\mathrm{n}, \mathrm{K})$ is a variety(over $\left.\mathrm{K}\right)$ if there exists forms $f_{1}, f_{2}, \ldots, f_{r}$ in $\mathrm{K}[\mathrm{x}]$ such that

$F=\left\{p(a) \in P G(n, K) \mid f_{1}(a)=f_{2}(a)=\cdots=f_{r}(a)=0\right\}=\mathrm{V}\left(f_{1}, f_{2}, \ldots, f_{r}\right)$.

Here, the points $p(\mathrm{a})$ are points of an $\mathrm{F}$.

\subsection{Definition [7]}

A point set of a conic is a $(q+1)$-arc of $P G(2, q)$.In $P G(2, q)$, q odd, every conic is complete as $(q+1)$-arc. $A(q+1)$-arc of $P G(2, q)$, q even, is always incomplete. It can be extended in a unique way to a $(q+2)$-arc by a point $r$ which is called the nucleus of this $(\mathrm{q}+1)$-arc [7].

\subsection{Theorem 1 ( B. Segre's famous theorem)[7]}

Every $(q+1)$-arc of $P G(2, q)$, $q$ odd, is a conic .

\subsection{Theorem 2 [8]}

In $\operatorname{PG}(2, \mathrm{q})$ with $\mathrm{q} \geq 4$, there is a unique conic through a 5-arc .

\subsection{Definition [7]}

An i-secant for $(k, n)-a r c$ is a line in $\mathrm{PG}(2, \mathrm{q})$ such that it contains exactly i points from this $(\mathrm{k}, \mathrm{n})$-arc.

\subsection{Theorem 3 [7]}

In $\mathrm{PG}(2, \mathrm{q}), \mathrm{q} \equiv-1 \bmod 4$, there exists a complete $\mathrm{k}-\operatorname{arc}$ with $\mathrm{k}=(\mathrm{q}+5) / 2$. 


\subsection{Theorem 4 [7]}

In $P G(2, q), q$ even and $q \geq 8$, there exists a complete $k$-arc with $k=(q+4) / 2$.

\subsection{Definition [1]}

Let $\mathrm{K}$ be a $(\mathrm{k}, \mathrm{n})$-arc ,if the order of the plane is $\mathrm{q}$, then

$\mathrm{k} \leq 1+(\mathrm{q}+1)(\mathrm{n}-1)=\mathrm{qn}-\mathrm{q}+\mathrm{n}$ with equality if and only if every line intersects the arc in 0 or $n$ points. Arcs realizing the upper bound are called maximal arcs.

\subsection{Definition [12]}

Points of index zero are points which belong to $\mathrm{PG}(2, \mathrm{q})$ such that it does not belong to $(\mathrm{k}, \mathrm{n})$-arc nor to any $\mathrm{n}$-secant for this $(\mathrm{k}, \mathrm{n})$-arc .

\section{Construction of PG(2,13)[7],[10]}

The plane $\operatorname{PG}(2, \mathrm{q})$ contains $q^{2}+q+1$ points,$q^{2}+q+1$ lines , $\mathrm{q}+1$ points lying on every line and $q+1$ lines passing through every point. So, in $\operatorname{PG}(2,13)$ we will get 183 points and 183 lines and 14 points on every line and 14 lines through every point.

\subsection{Analytic View}

Any point of the plane $\mathrm{PG}(2, \mathrm{q})$ has the form of triple $\left(x_{0}, x_{1}, x_{2}\right)$ where $x_{0}, x_{1}$ and $x_{2}$ are elements of $\mathrm{GF}(\mathrm{q})$ with the exception of a triple consisting of three zero elements, two triples represent the same point if there exists $\lambda$ in $\mathrm{GF}(\mathrm{q}) \backslash\{0\}$, such that

$\left(y_{0}, y_{1}, y_{2}\right)=\lambda\left(x_{0}, x_{1}, x_{2}\right)$.

Similarly, any line of the plane has the form of a triple $\left[x_{0}, x_{1}, x_{2}\right]$, where $x_{0}, x_{1}$ and $x_{2}$ are in $\mathrm{GF}(\mathrm{q})$ with the exception of a triple consisting three zero elements. Two lines $\left[x_{0}, x_{1}, x_{2}\right]$ and $\left[y_{0}, y_{1}, y_{2}\right]$ represent the same line if there exists $\lambda$ in $\mathrm{GF}(\mathrm{q}) \backslash\{0\}$ such that

$\left[y_{0}, y_{1}, y_{2}\right]=\lambda\left[x_{0}, x_{1}, x_{2}\right]$.

The point $\left(x_{0}, x_{1}, x_{2}\right)$ is incident with the line $\left[y_{0}, y_{1}, y_{2}\right]$ if $x_{0} y_{0}+x_{1} y_{1}+x_{2} y_{2} \equiv$ $0 \bmod q$.

\subsection{Construction of Lines and Points for PG(2,13)}

Firstly: Let us construct the points of $\mathrm{PG}(2,13)$ using lexical manner(A related industry lexical, linguistic style Dictionary i.e. reordering elements in ascending or descending order for each coordinate to any projective point) as in the following way :

Without the loss of generality, we can take $p_{1}=(1,0,0)$ be the first point ,then we can use all the plane's rest points as follows :

$p_{k}=(i, 1,0), \mathrm{i}=0,1, \ldots, 12 ;(\mathrm{k}=\mathrm{i}+2)$. Then, let $p_{k}=(i, j, 1), \mathrm{i}=0,1, \ldots, 12$ for each $\mathrm{j}=0,1, \ldots, 12$.(Here $\mathrm{k}$ runs from 15 up to 183 ).

This will collect all the points of $\mathrm{PG}(2,13)$ in lexical form. Now write each point in an independent row

Secondly: For simplicity, think of coordinates of each point as the coordinates for the line you want to construct (this implies that we think of the point coordinates $\left(x_{0}, x_{1}, x_{2}\right)$ as the line $\left[x_{0}, x_{1}, x_{2}\right]$ and the index $\mathrm{k}$ of the point is the same index $\mathrm{k}$ of the line). Now, you can choose the position of the points (their index) to write it beside the coordinate of the line according to the relation:

The point $\left(x_{0}, x_{1}, x_{2}\right)$ is incident with the line $\left[y_{0}, y_{1}, y_{2}\right]$ if $x_{0} y_{0}+x_{1} y_{1}+x_{2} y_{2} \equiv$ $0 \bmod 13$.

So, we will get the following $\mathrm{PG}(2,13)$ plane : 
First line :

Line index : $\mathrm{k}=1$, Line coordinates $=[1,0,0]$,

Line Points $=\{2,15,28,41,54,67,80,93,106,119,132,145,158$ and 171$\}$

Second line :

Line index : $\mathrm{k}=2$, Line coordinates $=[0,1,0]$,

Line Points $=\{1,15,16,17,18,19,20,21,22,23,24,25,26$ and 27$\}$,

Third line :

Line index : $k=3$,Line coordinates $=[1,1,0]$,

Line Points $=\{14,15,40,52,64,76,88,100,112,124,136,148,160$ and 172$\}$

and so on ...(all points and lines are in the Appendix )

Fifteenth line:

Line index : $\mathrm{k}=15$, Line coordinates $=[0,0,1]$,

Line Points $=\{1,2,3,4,5,6,7,8,9,10,11,12,13$ and 14$\}$

For example, note that (just for check) if you take the coordinates for the fifteenth line, you will take the vector $\left[y_{0}, y_{1}, y_{2}\right]=[0,0,1]$, now, choose the points that their coordinates $\left(x_{0}, x_{1}, x_{2}\right)$ are perpendicular to $[0,0,1]$,clearly $\left(x_{0}, x_{1}, x_{2}\right)=(1,0,0)$ is one of them which has index $\mathrm{k}=1$, so as $\left(x_{0}, x_{1}, x_{2}\right)=(0,1,0)$ which has index $\mathrm{k}=2$, also $\left(x_{0}, x_{1}, x_{2}\right)=(1,1,0)$ has $\mathrm{k}=3,\left(x_{0}, x_{1}, x_{2}\right)=(2,1,0)$ of index 4 , and so on ... Last line will be :

Line index: $\mathrm{k}=183$, Line coordinates $=[12,12,1]$,

Line Points $=\{14,16,28,53,65,77,89,101,113,125,137,149,161$ and 173$\}$

\section{The Fundamental Arc}

The fundamental theorem of projective geometry states that in any non-trivial projective space, there are four points, no three of them are collinear. Without the loss of generality, we can take an $s_{1}=(1,0,0), s_{2}=(0,1,0), s_{3}=(0,0,1)$ and $s_{4}=(1,1,1)$ because in finite projective geometry the relation $\mathrm{x}=\lambda \mathrm{x} \forall \mathrm{x} \in \mathrm{GF}(\mathrm{q}) \backslash\{0\}$ is achieved .It is clear that the coordinates of $s_{1}, s_{2}, s_{3}$ and $s_{4}$ are the simplest coordinates that can be taken. From now and on, we call the arc that contains from the simplest four points $\left\{s_{1}, s_{2}, s_{3}\right.$ and $\left.s_{4}\right\}$ by the fundamental arc. In our $\mathrm{PG}(2,13)$ fundamental arc is the points $\{1,2,15$ and 29$\}$, clearly it is a $(4,2)$-arc and it is not complete.

\subsection{Geometrical Representation of fundamental arc [10]}

According to the fundamental theorem in projective geometry there are four points (namely fundamental arc here) no three of them are collinear, so there is a line connecting each two points of them, this implies that there are six common lines as follows:

$\mathrm{L} 15=\overleftrightarrow{(1,2)}=\{1,2,3,4,5,6,7,8,9,10,11,12,13$ and 14$\}$;

$\mathrm{L} 2=\overleftrightarrow{(1,15)}=\{1,15,16,17,18,19,20,21,22,23,24,25,26$ and 27$\}$;

$\mathrm{L} 171=\overleftrightarrow{(1,29)}=\{1,28,29,30,31,32,33,34,35,36,37,38,39$ and 40$\}$;

$\mathrm{L} 1=\overleftrightarrow{(2,15)}=\{2,15,28,41,54,67,80,93,106,119,132,145,158$ and 171$\}$;

$\mathrm{L} 27=\overleftrightarrow{(2,29)}=\{2,16,29,42,55,68,81,94,107,120,133,146,159$ and 172$\}$;

$\mathrm{L} 14=\overleftrightarrow{(15,29)}=\{3,15,29,43,57,71,85,99,113,127,141,155,169$ and 183$\}$;

Now, if we plot these lines according to fundamental arc we will get the following figure: 


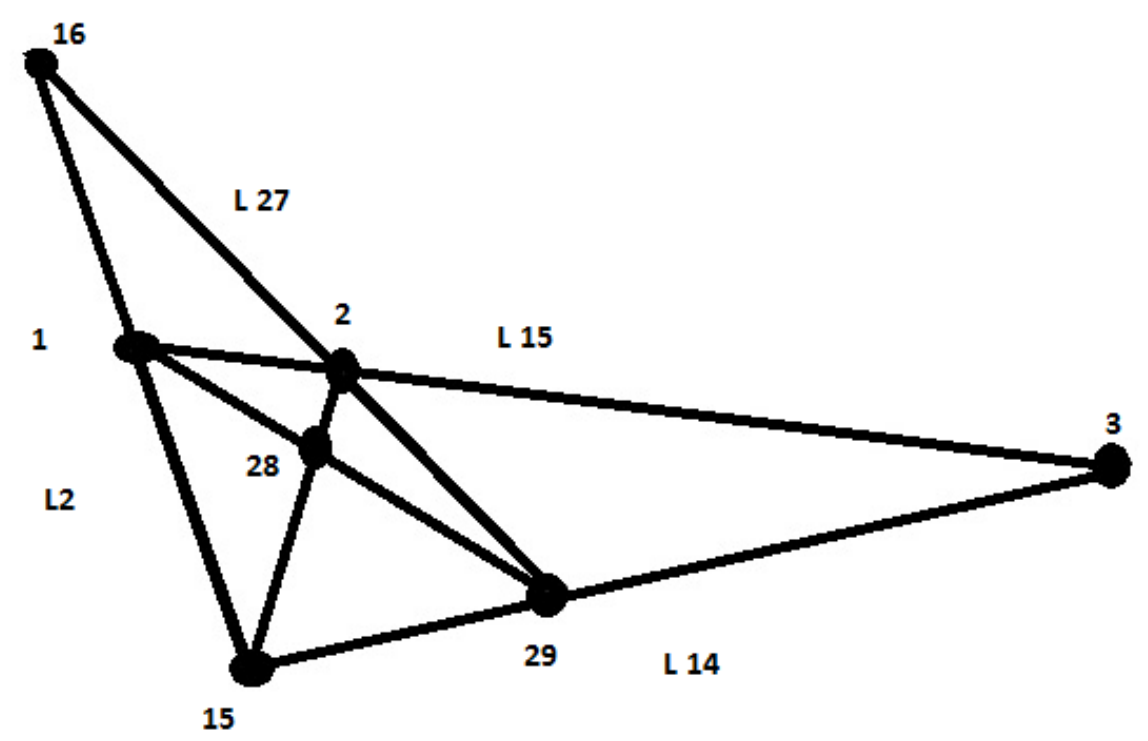

Figure(1) presents the six lines of the fundamental arc with its diagonal points

We see from figure (1) that the diagonal points are $\{3,16$ and 28$\}$ which arise from the intersection of each two lines from the six lines as follows:

$L 14 \cap L 15=\{3\}, L 2 \cap L 27=\{16\}, L 1 \cap L 171=\{28\}$.

\section{Construction of Complete $(k, 2)$-arcs}

In this section, we build all the conics that are containing the fundamental arc. So, take the variety $\mathrm{V}(2)$ in general manner as done in[10]

$V\left(x_{0}, x_{1}, x_{2}\right)=a_{1} x_{0}^{2}+a_{2} x_{1}^{2}+a_{3} x_{2}^{2}+a_{4} x_{0} x_{1}+a_{5} x_{0} x_{2}+a_{6} x_{1} x_{2}=0$, $a_{i} \in G F(13)$

Substitute fundamental arc point coordinates in (1) we get

$\mathrm{V}\left(\mathrm{s}_{1}\right)=\mathrm{V}(1,0,0)=0 \Rightarrow \mathrm{a}_{1}=0$

$\mathrm{V}\left(\mathrm{s}_{2}\right)=\mathrm{V}(0,1,0)=0 \Rightarrow \mathrm{a}_{2}=0$

$\mathrm{V}\left(\mathrm{s}_{3}\right)=\mathrm{V}(0,0,1)=0 \Longrightarrow \mathrm{a}_{3}=0$

$\mathrm{V}\left(\mathrm{s}_{4}\right)=\mathrm{V}(1,1,1)=0 \Rightarrow \mathrm{a}_{4}+\mathrm{a}_{5}+\mathrm{a}_{6}=0$

So,(1) becomes

$a_{4} x_{0} x_{1}+a_{5} x_{0} x_{2}+a_{6} x_{1} x_{2}=0$,

Now, if $\mathrm{a}_{4}=0 \Longrightarrow \mathrm{x}_{2}\left(\mathrm{a}_{5} \mathrm{x}_{0}+\mathrm{a}_{6} \mathrm{x}_{1}\right)=0 \Longrightarrow$ it is degenerated (It can be expressed as a product of the two factors) $\Longrightarrow a_{4}$ must not be zero. Similarly, $a_{5} \neq 0$ and $a_{6} \neq 0$. Dividing eq.(2) by a4 we get

$x_{0} x_{1}+\alpha x_{0} x_{2}+\beta x_{1} x_{2}=0$,

$\alpha=\frac{a_{5}}{a_{4}}, \beta=\frac{a_{6}}{a_{4}}$, Now substitute s4 we get

$1+\alpha+\beta=0 \Rightarrow \beta=-(1+\alpha)$, Now $\alpha \neq 0 \& \alpha \neq 12$ because if not then, it will be degenerated (For contradicting, let $\alpha=0$ this implies $=-1$, now substitute this in (3) we get $x_{0} x_{1}-x_{1} x_{2}=0 \Rightarrow x_{1}\left(x_{0}-x_{2}\right)=0$ this means (3) degenerate ), so it must be $\alpha=1,2, \ldots, 11$.

Now, we can run our work on different values of $\alpha$ to get the conics that contains the fundamental arc,So

1- If $\alpha=1$, then eq.(3) becomes the conic $C_{1}=x_{0} x_{1}+x_{0} x_{2}+11 x_{1} x_{2}=0$ have the points $\{1,2,15,29,51,62,79,86,104,111,128,139,148$ and 162$\}$ when check the number of points of index zero, we see it zero. So, $C_{1}$ is complete $(14,2)$-arc. 
2- If $\alpha=2$, then eq.(3) becomes the conic $C_{2}=x_{0} x_{1}+2 x_{0} x_{2}+10 x_{1} x_{2}=0$ have the points $\{1,2,15,29,49,61,69,84,105,117,124,138,154$ and 181$\}$ when check the number of points of index zero we see it zero. So, $C_{2}$ is complete $(14,2)$-arc.

3- If $\alpha=3$, then eq.(3) becomes the conic $C_{3}=x_{0} x_{1}+3 x_{0} x_{2}+9 x_{1} x_{2}=0$ have the points $\{1,2,15,29,53,56,73,89,100,114,129,135,163$ and 182$\}$ when check the number of points of index zero we see it zero. So, $C_{3}$ is complete $(14,2)$-arc.

4- If $\alpha=4$, then eq.(3) becomes the conic $C_{4}=x_{0} x_{1}+4 x_{0} x_{2}+8 x_{1} x_{2}=0$ have the points $\{1,2,15,29,47,58,76,90,96,108,131,156,166$ and 178$\}$ when check the number of points of index zero we see it zero. So, $C_{4}$ is complete $(14,2)$-arc.

5- If $\alpha=5$, then eq.(3) becomes the conic $C_{5}=x_{0} x_{1}+5 x_{0} x_{2}+7 x_{1} x_{2}=0$ have the points $\{1,2,15,29,52,66,74,83,101,116,134,149,167$ and 176$\}$ when check the number of points of index zero we see it zero. So, $C_{5}$ is complete $(14,2)$-arc.

6- If $\alpha=6$, then eq.(3) becomes the conic $C_{6}=x_{0} x_{1}+6 x_{0} x_{2}+6 x_{1} x_{2}=0$ have the points $\{1,2,15,29,46,65,75,82,103,123,144,151,161$ and 180$\}$ when check the number of points of index zero we see it zero. So, $C_{6}$ is complete $(14,2)$-arc.

7- If $\alpha=7$, then eq.(3) becomes the conic $C_{7}=x_{0} x_{1}+7 x_{0} x_{2}+5 x_{1} x_{2}=0$ have the points $\{1,2,15,29,50,59,77,92,110,125,143,152,160$ and 174$\}$ when check the number of points of index zero we see it zero. So, $C_{7}$ is complete $(14,2)$-arc.

8- If $\alpha=8$, then eq.(3) becomes the conic $C_{8}=x_{0} x_{1}+8 x_{0} x_{2}+4 x_{1} x_{2}=0$ have the points $\{1,2,15,29,48,60,70,95,118,130,136,150,168$ and 179$\}$ when check the number of points of index zero we see it zero. So, $C_{8}$ is complete $(14,2)$-arc.

9- If $\alpha=9$, then eq.(3) becomes the conic $C_{9}=x_{0} x_{1}+9 x_{0} x_{2}+3 x_{1} x_{2}=0$ have the points $\{1,2,15,29,44,63,91,97,112,126,137,153,170$ and 173$\}$ when check the number of points of index zero we see it zero. So, $\mathrm{C}_{9}$ is complete $(14,2)$-arc.

10- If $\alpha=10$, then eq. (3) becomes the conic $C_{10}=x_{0} x_{1}+10 x_{0} x_{2}+2 x_{1} x_{2}=0$ have the points $\{1,2,15,29,45,72,88,102,109,121,142,157,165$ and 177$\}$ when check the number of points of index zero we see it zero. So, $\mathrm{C}_{10}$ is complete $(14,2)$-arc.

11- If $\alpha=11$, then eq.(3) becomes the conic $C_{11}=x_{0} x_{1}+11 x_{0} x_{2}+x_{1} x_{2}=0$ have the points $\{1,2,15,29,64,78,87,98,115,122,140,147,164$ and 175$\}$ when check the number of points of index zero we see it zero. So, $\mathrm{C}_{11}$ is complete (14,2)-arc.

\section{Construction of complete $(k, n)$-arcs for $n=3, \ldots, 11$}

First we must put an important condition to do this construction, we strongly recommended that must each complete $(\mathrm{k}, \mathrm{n})$-arc contains the fundamental arc with all of its four points and not eliminate any point from it for any reason or process in constructing the complete $(\mathrm{k}, \mathrm{n})$-arcs. This paper distinguishes with this condition because the derivation of the conics (in section 5) depends on the coordinates of the fundamental arc points. So, we will do the same way as [9], but we will be far away from his mistakes of eliminating some points from fundamental arc (he eliminate the point 17 to form the $\mathrm{F}_{2}$ and eliminate the point 9 to get $\mathrm{G}$, while these two points are two from the four points of fundamental arc in $\mathrm{PG}(2,7))$.

Man sometimes does some mistakes(for example in[9], the point 5 does not belong to the points of zero index for $\mathrm{D}_{1}$, but he writes it as a point of zero index), for this reason, I write a MATLAB ${ }^{\circledR}$ script and run it (after check it on $\operatorname{PG}(2,5), \operatorname{PG}(2,7)$ and PG $(2,11))$ to get the correct results on PG(2,13),I program it to find all the conics and all the different combinations of the different conics to get the $(\mathrm{k}, 3)$-arcs, so the number of all combinations are $C_{2}^{11}=\frac{11 !}{2 !(11-2) !}=55$ cases ,but if we continue evaluating for $(\mathrm{k}, 4)$-arcs we will see that $C_{2}^{55}=\frac{55 !}{2 !(55-2) !}=1485$ cases, for $(\mathrm{k}, 5)$-arcs and upper, this 
number will be increased into bigger and bigger numbers. Because of these huge numbers, this research is made for constructing, not for classifying, so we can take determined numbers for each $(\mathrm{k}, \mathrm{n})$-arcs, so I see to take firstly the whole 55 cases and, then take (55+1)/2 different cases and, then take 55 cases and so on alternatively .

According to last paragraph, the numbers of $(\mathrm{k}, 3)$-arcs, $(\mathrm{k}, 5)$-arcs, $(\mathrm{k}, 7)$-arcs, $(\mathrm{k}, 9)$-arcs and $(\mathrm{k}, 11)$-arcs are 55 different cases for each one of them and the numbers of $(\mathrm{k}, 4)$-arcs, $(\mathrm{k}, 6)$-arcs, $(\mathrm{k}, 8)$-arcs, $(\mathrm{k}, 10)$-arcs and $(\mathrm{k}, 12)$-arcs are 28 different cases for each one of them.

The program can compute and save other things like the details for each $(\mathrm{k}, \mathrm{n})$-arc and which points are to be added and which points must be eliminated (here, it avoids any point from fundamental arc), save the history of each $(k, n)$-arc came from, save the spectrum for each complete $(k, n)$-arc and save the complete $(k, n)$-arc itself, furthermore all this different information is stored in just one variable of class 'structure'.

In the following subsections (6.2 up to 6.10), we will write just one example for simplicity, except in section 6.1 , we will write two examples to show how the process works ,but if anyone likes to see all the results, he(or she) can contact with the researcher.

\subsection{Construction of Complete $(k, 3)$-arcs}

Using the union of each two different conics from section 5 as follows:

Let $D_{t}=C_{i} \cup C_{j}$ where $i<j, \forall i, j=1,2, \ldots, 11 ; t=1,2, \ldots, 55$.

For example, $D_{1}=C_{1} \cup C_{2}=\{1,2,15,29,49,51,61,62,69,79,84,86,104,105,111,117,124$, $128,138,139,148,154,162$ and 181$\}$ it is a $(24, n)-a r c$, but this set of points needs some operations like\{-148-154-139-111-162-124-138+162+164+113+119\}, to get the complete $(\mathrm{k}, 3)$-arc (here the minus sign means eliminating the following point while the plus sign means adding the following point). This means the operations which had been done on $\mathrm{D}_{1}$, are first step: eliminates the point 148 from $\mathrm{D}_{1}$, second step: eliminates the point 154 from result of first step, and so on ...,eighth step: adds the point 162 to the result of seventh step, and so on ... . The $(\mathrm{k}, 3)$-arc will be $(21,3)$-arc which its points are $\{1,2,15,29,49,51,61,62,69,79,84,86,104,105,117,128,181,162,164,113$ and 119 \}, which has no points of index zero, so it is complete $(21,3)$-arc. The spectrum for this complete (21,3)-arc is $\tau_{0,1,2,3}=[42,45,39$ and 57] respectively.

Another example $: D_{55}=C_{10} \cup C_{11}=\{1,2,15,29,45,64,72,78,87,88,98,102,109$, $115,121,122,140,142,147,157,164,165,175$ and 177$\}$ it is a $(24, n)$-arc, but this set of points needs some operations like $\{-165-98-177-164-175-142-157+48+104\}$, to get the complete $(\mathrm{k}, 3)$-arc. The $(\mathrm{k}, 3)$-arc will be $(19,3)$-arc which its points are $\{1,2,15,29,45,64$, $72,78,87,88,102,109,115,121,122,140,147,48$ and 104$\}$,checking the plane with this $(19,3)$-arc we can see it has no points of index zero, so it is complete $(19,3)$-arc. The spectrum for this complete $(19,3)$-arc is $\tau_{0,1,2,3}=[47,47,48$ and 41] respectively.

\subsection{Construction of Complete $(k, 4)-\operatorname{arcs}$}

Let $E_{t}=D_{i} \cup D_{j}$ where $i<j, \forall i=1,3,5, \ldots, 53, j=i+1 ; t=1,2, \ldots, 28$ and let $E_{28}=D_{55} \cup D_{54}$. This selection of $i$ 's and $j^{\prime} s$ makes using of all different $D_{i}$ in minimum number of $t$ cases.

Example : Take $\mathrm{t}=12 \Longrightarrow E_{12}=D_{23} \cup D_{24}=\{1,2,15,29,26,32,48,50,53,56,59,60,70,73$, $77,89,92,95,99,100,110,114,118,124,129,135,136,165$ and 182$\}$ it is $(29, n)$-arc, but this set of points needs some operations like $\{-182-165+24+5+6+130\}$ to get the complete $(\mathrm{k}, 4)$-arc. The $(29, \mathrm{n})$-arc will be $(31,4)$-arc which its points are : $\{1,2,15,29,26,32,48,50$, $53,56,59,60,70,73,77,89,92,95,99,100,110,114,118,124,129,135,136,24,5,6$ and 130$\}$, 
which has zero number of points of index zero, so it is complete $(31,4)$-arc. The spectrum for this complete $(31,4)$-arc is $\tau_{o, \ldots, 4}=[24,27,36,49$ and 47$]$ respectively.

\subsection{Construction of Complete $(k, 5)$-arcs}

Let $F_{t}=E_{i} \cup E_{j}$ where $i<j, i, j=1,2, \ldots, 11 ; t=1,2, \ldots, 55$.

Example : Take $\mathrm{t}=17 \Longrightarrow F_{17}=E_{2} \cup E_{9}=\{1,2,15,29,7,8,9,18,19,28,30,44,45,47,49,51$, $52,58,61,62,63,66,69,72,74,76,79,83,84,86,88,90,91,96,97,101,102,104,105,109,111$, $112,117,126,127,135,137,140,142,150,154,160,177$ and 180$\}$ it is $(54, n)-a r c$, but this set of points needs some operations like $\{-160-180-137-154-177-150-97-135-109-140-127$ $-142-105-79-66-91-90-52-51-88+118+21+146+87+134+154+120\}$ to get the complete $(\mathrm{k}, 5)$-arc. The $(54, \mathrm{n})$-arc will be $(41,5)$-arc which its points are : $\{1,2,15,29,7,8,9,18,19$, $28,30,44,45,47,49,58,61,62,63,69,72,74,76,83,84,86,96,101,102,104,111,112,117,126$, $118,21,146,87,134,154$ and 120 , which has zero number of points of index zero, so it is complete $(41,5)$-arc. The spectrum for this complete $(41,5)$-arc is $\tau_{o, \ldots, 5}=[11,18,33,37$, 41 and 43] respectively.

\subsection{Construction of Complete $(k, 6)$-arcs}

Let $G_{t}=F_{i} \cup F_{j}$ where $i<j, \forall i=1,3,5, \ldots, 53, j=i+1 ; t=1,2, \ldots, 28$ and let $G_{28}=F_{55} \cup F_{54}$.

Example : Take $\mathrm{t}=23 \Longrightarrow G_{23}=F_{45} \cup F_{46}=\{1,2,15,29,4,6,8,14,16,18,20,22,24,26,28$, $31,33,36,38,40,46,47,48,49,50,52,56,58,59,60,61,65,69,70,73,74,75,81,82,83,84,89,93$, $95,97,100,101,105,112,114,115,118,120,124,129,134,145,147,149,157,162,168,176$ and $180\}$ it is $(64, n)$-arc, but this set of points needs some operations like $\{-26-24-124-120$ 162-176-168-147-134-105-157-112-65-129-52-180-145-100-40-38+159+146+105+110 $+152+163+147+119+158+128\}$ to get the complete $(\mathrm{k}, 6)$-arc. The $(64, \mathrm{n})$-arc will be $(54,6)$-arc which its points are: $\{1,2,15,29,4,6,8,14,16,18,20,22,28,31,33,36,46,47,48$, $49,50,56,58,59,60,61,69,70,73,74,75,81,82,83,84,89,93,95,97,101,114,115,118,149,159$ $, 146,105,110,152,163,147,119,158$ and 128$\}$, which has zero number of points of index zero, so it is complete $(54,6)$-arc. The spectrum for this complete $(54,6)$-arc is $\tau_{o, \ldots, 6}=[4,10,19,27,41,29$ and 53] respectively.

\subsection{Construction of Complete $(k, 7)-\operatorname{arcs}$}

Let $H_{t}=G_{i} \cup G_{j}$ where $i<j, i, j=1,2, \ldots, 11 ; t=1,2, \ldots, 55$.

Example : Take $\mathrm{t}=6 \Longrightarrow H_{6}=G_{1} \cup G_{7}=\{1,2,15,29,3,4,6,7,8,16,18,19,24,26,28,30,31$, $34,35,39,41,45,46,47,49,50,51,56,58,59,61,62,64,69,72,73,74,75,76,82,83,84,86,87,88$, $89,96,97,99,100,101,102,104,107,108,111,112,113,115,119,127,128,129,133,135,137$, $144,146,158,160,162,163,164,167,168,181$ and 182$\}$ it is $(77, n)$-arc,but this set of points needs some operations like\{-163-182-167-162-164-128-104-168-181-89-51-133$158-129-115-119-39+110+161\}$ to get the complete $(\mathrm{k}, 7)$-arc. The $(77, \mathrm{n})$-arc will be $(62,7)$-arc which its points are : $\{1,2,15,29,3,4,6,7,8,16,18,19,24,26,28,30,31,34,35,41$, $45,46,47,49,50,56,58,59,61,62,64,69,72,73,74,75,76,82,83,84,86,87,88,96,97,99,100$, $101,102,107,108,111,112,113,127,135,137,144,146,160,110$ and 161$\}$, which has zero number of points of index zero, so it is complete $(62,7)$-arc. The spectrum for this complete $(62,7)$-arc is $\tau_{o, \ldots, 7}=[0,6,16,20,40,36,25$ and 40$]$ respectively.

\subsection{Construction of Complete $(\mathrm{k}, 8)$-arcs}

Let $I_{t}=H_{i} \cup H_{j}$ where $i<j, \forall i=1,3,5, \ldots, 53, j=i+1 ; t=1,2, \ldots, 28$ and let $I_{28}=H_{55} \cup H_{54}$. 
Example : Take $\mathrm{t}=14 \Longrightarrow I_{14}=H_{27} \cup H_{28}=\{1,2,15,29,3,4,5,6,8,9,10,16,18,19,20,21$, $22,24,28,30,31,33,34,35,38,41,43,44,45,46,47,48,49,51,56,58,59,60,61,62,65,69,70,72$, $73,74,75,76,81,82,83,84,86,87,88,95,96,97,98,100,101,106,107,108,110,111,113,114$, $115,116,117,118,119,122,123,127,140,145,146,154,159,164,174,180$ and 181$\}$ it is $(85, n)-a r c$, but this set of points needs some operations like $\{-24-174-10-140-113-164-$ 114-181-51-49-159-145-118-117-38-146+155+140+145+151+133+132\} to get the complete $(\mathrm{k}, 8)$-arc. The $(85, \mathrm{n})$-arc will be $(75,8)$-arc which its points are: $\{1,2,15,29,3,4$, $5,6,8,9,16,18,19,20,21,22,28,30,31,33,34,35,41,43,44,45,46,47,48,56,58,59,60,61,62,65$ ,69,70,72,73,74,75,76,81,82,83,84,86,87,88,95,96,97,98,100,101,106,107,108,110,111, $115,116,119,122,123,127,154,180,155,140,145,151,133$ and 132$\}$, which has zero number of points of index zero, so it is complete $(75,8)$-arc. The spectrum for this complete $(75,8)$-arc is $\tau_{o, \ldots, 8}=[0,2,6,11,31,29,34,30$ and 40$]$ respectively.

\subsection{Construction of Complete (k,9)-arcs}

Let $J_{t}=I_{i} \cup I_{j}$ where $i<j, i, j=1,2, \ldots, 11 ; t=1,2, \ldots, 55$.

Example : Take $\mathrm{t}=9 \Longrightarrow J_{9}=I_{1} \cup I_{10}=\{1,2,15,29,3,4,5,6,7,8,9,10,16,18,19,21,22,24,26$, $28,30,31,32,33,34,35,41,44,45,46,47,48,49,56,58,59,60,61,62,64,65,69,70,72,73,74,75$, $76,81,82,83,84,86,87,88,89,95,96,97,98,100,101,102,106,107,108,109,111,112,113,115$ ,117,118,119,120,121,122,123,124,127,131,132,133,137,140,141,147,150,151,157,168, 178 and 179$\}$ it is $(93, n)$-arc, but this set of points needs some operations like $\{-168-10$ $150-178-147-179-132-118-117-157+183+160+170+149+159+67+172+53\}$ to get the complete $(\mathrm{k}, 9)$-arc. The $(93, \mathrm{n})$-arc will be $(91,9)$-arc which its points are : $\{1,2,15$, $29,3,4,5,6,7,8,9,16,18,19,21,22,24,26,28,30,31,32,33,34,35,41,44,45,46,47,48,49,56,58$, $59,60,61,62,64,65,69,70,72,73,74,75,76,81,82,83,84,86,87,88,89,95,96,97,98,100,101$, $102,106,107,108,109,111,112,113,115,119,120,121,122,123,124,127,131,133,137,140$, $141,151,183,160,170,149,159,67,172$ and 53 , which has no points of index zero, so it is complete $(91,9)$-arc. The spectrum for this complete $(91,9)$-arc is $\tau_{o, \ldots, 9}=[0,0,2,6,11,23$, 27,30,35 and 49] respectively.

\subsection{Construction of Complete $(\mathrm{k}, 10)$-arcs}

Let $K_{t}=J_{i} \cup J_{j}$ where $i<j, \forall i=1,3,5, \ldots, 53, j=i+1 ; t=1,2, \ldots, 28$ and let $K_{28}=J_{55} \cup J_{54}$.

Example : Take $\mathrm{t}=20 \Rightarrow K_{20}=J_{39} \cup J_{40}=\{1,2,15,29,3,4,5,6,7,8,9,16,17,18,19,20,21$, $22,24,28,30,31,32,33,34,35,41,43,44,45,46,47,48,49,51,54,56,58,59,60,61,62,64,65,69$, $70,72,73,74,75,76,77,81,82,83,84,86,87,88,89,95,96,97,98,100,101,102,103,104,106$, $107,108,109,110,111,112,113,119,120,121,122,123,124,127,128,129,132,133,136,138$, $140,141,144,149,153,159,163,165,167,168,169,171$ and 176$\}$ it is $(103, n)-a r c$, but this set of points needs some operations like $\{-149-176-171-168-169-163+132+167+$ $38+146+157+92+167+68+114+154\}$ to get the complete $(\mathrm{k}, 10)$-arc. The $(103, \mathrm{n})$-arc will be $(107,10)$-arc which its points are: $\{1,2,15,29,3,4,5,6,7,8,9,16,17,18,19,20,21$, $22,24,28,30,31,32,33,34,35,41,43,44,45,46,47,48,49,51,54,56,58,59,60,61,62,64,65,69$, $70,72,73,74,75,76,77,81,82,83,84,86,87,88,89,95,96,97,98,100,101,102,103,104,106$, $107,108,109,110,111,112,113,119,120,121,122,123,124,127,128,129,132,133,136,138$, $140,141,144,153,159,165,167,132,167,38,146,157,92,167,68,114$ and 154 , which has no points of index zero, so it is complete $(107,10)$-arc. The spectrum for this complete $(107,10)$-arc is $\tau_{o, \ldots, 10}=[0,1,0,1,3,12,26,24,37,30$ and 49$]$ respectively.

\subsection{Construction of Complete $(k, 11)-\operatorname{arcs}$}

Let $L_{t}=K_{i} \cup K_{j}$ where $i<j, i, j=1,2, \ldots, 11 ; t=1,2, \ldots, 55$. 
Example : Take $\mathrm{t}=13 \Longrightarrow L_{13}=K_{2} \cup K_{5}=\{1,2,15,29,3,4,5,6,7,8,9,13,14,16,17,18,19$, $20,21,22,24,26,28,30,31,32,33,34,35,36,41,43,44,45,46,47,48,49,53,54,55,56,58,59,60$, $61,62,63,64,65,67,69,70,72,73,74,75,76,77,79,80,81,82,83,84,86,87,88,89,93,95,96,97$, $98,100,101,102,103,104,106,107,108,109,110,111,112,113,115,116,119,120,121,122$, $123,124,125,127,128,129,131,133,135,136,137,140,141,142,144,147,148,150,151,153$, $154,156,158,164,165,166,167,169,170$ and 178$\}$ it is $(123, n)$-arc,but this set of points needs some operations like $\{-170-165-65-147-158-131-166-156+145+149+155+52\}$ to get the complete $(\mathrm{k}, 11)$-arc. The $(123, \mathrm{n})$-arc will be $(119,11)$-arc which its points are $\{1,2,15,29,3,4,5,6,7,8,9,13,14,16,17,18,19,20,21,22,24,26,28,30,31,32,33,34,35,36,41$, $43,44,45,46,47,48,49,53,54,55,56,58,59,60,61,62,63,64,67,69,70,72,73,74,75,76,77,79$, $80,81,82,83,84,86,87,88,89,93,95,96,97,98,100,101,102,103,104,106,107,108,109,110$, $111,112,113,115,116,119,120,121,122,123,124,125,127,128,129,133,135,136,137,140$, $141,142,144,148,150,151,153,154,164,167,169,178,145,149,155$ and 52$\}$, which has no points of index zero, so it is complete $(119,11)$-arc. The spectrum for this complete $(119,11)$-arc is $\tau_{o, \ldots, 11}=[0,0,1,0,2,2,9,18,29,33,42$ and 47$]$ respectively.

\subsection{Construction of Complete $(k, 12)$-arcs}

Let $M_{t}=L_{i} \cup L_{j}$ where $i<j, \forall i=1,3,5, \ldots, 53, j=i+1 ; t=1,2, \ldots, 28$ and let $M_{28}=L_{55} \cup L_{54}$.

Example : Take $\mathrm{t}=15 \Rightarrow M_{15}=L_{29} \cup L_{30}=\{1,2,15,29,3,4,5,6,7,8,9,10,11,16,17,18$, $19,20,21,22,24,25,28,30,31,32,33,34,35,36,37,40,41,42,43,44,45,46,47,48,49,52,53,54$, $56,58,59,60,61,62,63,64,65,67,68,69,70,71,72,73,74,75,76,78,81,82,83,84,86,87,88,89$, $90,91,93,94,95,96,97,98,99,100,101,102,106,107,108,109,110,111,112,113,114,115$, $119,120,121,122,123,124,127,128,129,130,132,133,135,136,137,139,140,141,142,143$, $144,145,148,150,151,152,153,154,155,159,160,161,169$ and 178$\}$ it is $(128, n)$-arc, but this set of points needs some operations like $\{+171+118+23+56+131+164+85+66+168$ $+149\}$ to get the complete $(\mathrm{k}, 12)$-arc. The $(128, \mathrm{n})$-arc will be $(138,12)$-arc which its points are: $\{1,2,15,29,3,4,5,6,7,8,9,10,11,16,17,18,19,20,21,22,24,25,28,30,31,32,33$, $34,35,36,37,40,41,42,43,44,45,46,47,48,49,52,53,54,56,58,59,60,61,62,63,64,65,67,68$, $69,70,71,72,73,74,75,76,78,81,82,83,84,86,87,88,89,90,91,93,94,95,96,97,98,99,100$, $101,102,106,107,108,109,110,111,112,113,114,115,119,120,121,122,123,124,127,128$, $129,130,132,133,135,136,137,139,140,141,142,143,144,145,148,150,151,152,153,154$, $155,159,160,161,169,178,171,118,23,56,131,164,85,66,168$ and 149$\}$, which has no points of index zero, so it is complete $(138,12)$-arc. The spectrum for this complete $(138,12)$-arc is $\tau_{o, \ldots, 12}=[0,0,0,1,0,0,2,7,8,28,28,50$ and 59] respectively.

\subsection{Construction of Complete $(k, 13)$-arcs}

It is clearly from [7] that the simple way to get the complete $(\mathrm{k}, 13)$-arcs is to eliminate one line from the plane PG(2,13) and get the complete $(169,13)$-arc. So, using this idea on any line that does not contain any point from the fundamental arc will get the result.

\subsection{Construction of Complete $(k, 14)$-arcs}

Clearly from [7], the whole plane is the only one choice to get the complete $(183,14)$-arc in $\mathrm{PG}(2,13)$. 


\section{REFERENCES}

[1] Ball, S., Blokhuis, A. , (1999),"On the incompleteness of (k,n)-arcs in Desarguesian planes of order q where n divides q", Geometriae Dedicata , Volume 74, Issue 3, pp 325-332.

[2] Ball, S., Hirschfeld, J.W.P., (2005), "Bounds on (n,r)-arcs and their applications to linear codes", Finite Fields and Their Applications, 11, pp. 326-336.

[3] Bartoli, D., Faina G., Marcugini S. and Pambianco F.,(2013),"A new algorithm and a new type of estimate for the smallest size of complete arcs in $\mathrm{PG}(2, \mathrm{q}) "$, Elsevier Electronic Notes in Discrete Mathematics 40,27-31.

[4] Cheon, E. J., (2012)," On the (29;5)-arcs in PG(2;7) and linear codes",Department of Mathematics and RINS Gyeongsang National University, Korea

[5] Daskalov, R., (2004) "'On the existence and the nonexistence of some (k, r)-arcs in PG(2,17)", in Proc. of Ninth International Workshop on Algebraic and Combinatorial Coding Theory, 19-25, Kranevo, Bulgaria, pp. 95-100.

[6] Daskalov, R., (2008 ), “On the maximum size of some (k, r)-arcs in PG(2, q)”, Discrete Mathematics, vol. 308, no. 4, pp. 565-570.

[7] Hirschfeld,J.W.P., (1979), ' Projective Geometries Over Finite Fields ' , Oxford University Press.

[8] Hughes, D.R. , Piper, F. C., (1973), " Projective Planes ", Springerverlag, new York Inc .

[9] Ismaeel, N.A., (2012),"Construction Of Complete And Maximal (K, N) Arcs In The Projective Plane PG $(2,7) "$,Diyala Journal for Pure Sciences, Vol: 8 No: 1.

[10] Kadhum, S.J., (2010), " The Maximum Complete (k,n)-Arcs in the Projective Plane PG(2,4) By Geometric Method", Ibn Al- Haitham J. For Pure \& Appl. Sc I. Vol.23 (1).

[11] Marcugini, S., (2005),"Maximal (n, 3)-arcs in PG(2, 13)", Discrete Mathematics 294,139-145.

[12] Mohammad, H.H., (2006)"The Maximum Size of (n,r)-Arcs In The Projective Plane PG(2,q)",M.Sc. Thesis ,Mosul University.

[13] Yasin, A. L., (1986)"Cubic arcs in the projective plane of order eight", Ph.D. Thesis, University of Sussex. 


\section{Appendix}

Points and Lines for PG(2,13)

\begin{tabular}{|c|c|c|c|c|c|c|c|c|c|c|c|c|c|c|c|c|c|}
\hline $\mathbf{P}_{\mathrm{i}}$ & $\mathbf{X}_{\mathbf{0}}$ & $\mathbf{X}_{1}$ & $\mathbf{X}_{2}$ & \multicolumn{14}{|c|}{$\mathbf{L}_{\mathbf{i}}$} \\
\hline 1 & 1 & 0 & 0 & 2 & 15 & 28 & 41 & 54 & 67 & 80 & 93 & 106 & 119 & 132 & 145 & 158 & 171 \\
\hline 2 & 0 & 1 & 0 & 1 & 15 & 16 & 17 & 18 & 19 & 20 & 21 & 22 & 23 & 24 & 25 & 26 & 27 \\
\hline 3 & 1 & 1 & $\mathbf{0}$ & 14 & 15 & 40 & 52 & 64 & 76 & 88 & 100 & 112 & 124 & 136 & 148 & 160 & 172 \\
\hline 4 & 2 & 1 & $\mathbf{0}$ & 8 & 15 & 34 & 53 & 59 & 78 & 84 & 103 & 109 & 128 & 134 & 153 & 159 & 178 \\
\hline 5 & 3 & 1 & 0 & 6 & 15 & 32 & 49 & 66 & 70 & 87 & 104 & 108 & 125 & 142 & 146 & 163 & 180 \\
\hline 6 & 4 & 1 & 0 & 5 & 15 & 31 & 47 & 63 & 79 & 82 & 98 & 114 & 130 & 133 & 149 & 165 & 181 \\
\hline 7 & 5 & 1 & 0 & 7 & 15 & 33 & 51 & 56 & 74 & 92 & 97 & 115 & 120 & 138 & 156 & 161 & 179 \\
\hline 8 & 6 & 1 & 0 & 4 & 15 & 30 & 45 & 60 & 75 & 90 & 105 & 107 & 122 & 137 & 152 & 167 & 182 \\
\hline 9 & 7 & 1 & 0 & 13 & 15 & 39 & 50 & 61 & 72 & 83 & 94 & 118 & 129 & 140 & 151 & 162 & 173 \\
\hline 10 & 8 & 1 & 0 & 10 & 15 & 36 & 44 & 65 & 73 & 81 & 102 & 110 & 131 & 139 & 147 & 168 & 176 \\
\hline 11 & 9 & 1 & 0 & 12 & 15 & 38 & 48 & 58 & 68 & 91 & 101 & 111 & 121 & 144 & 154 & 164 & 174 \\
\hline 12 & 10 & 1 & 0 & 11 & 15 & 37 & 46 & 55 & 77 & 86 & 95 & 117 & 126 & 135 & 157 & 166 & 175 \\
\hline 13 & 11 & 1 & 0 & 9 & 15 & 35 & 42 & 62 & 69 & 89 & 96 & 116 & 123 & 143 & 150 & 170 & 177 \\
\hline 14 & 12 & 1 & 0 & 3 & 15 & 29 & 43 & 57 & 71 & 85 & 99 & 113 & 127 & 141 & 155 & 169 & 183 \\
\hline 15 & 0 & 0 & 1 & 1 & 2 & 3 & 4 & 5 & 6 & 7 & 8 & 9 & 10 & 11 & 12 & 13 & 14 \\
\hline 16 & 1 & 0 & 1 & 2 & 27 & 40 & 53 & 66 & 79 & 92 & 105 & 118 & 131 & 144 & 157 & 170 & 183 \\
\hline 17 & 2 & 0 & 1 & 2 & 21 & 34 & 47 & 60 & 73 & 86 & 99 & 112 & 125 & 138 & 151 & 164 & 177 \\
\hline 18 & 3 & 0 & 1 & 2 & 19 & 32 & 45 & 58 & 71 & 84 & 97 & 110 & 123 & 136 & 149 & 162 & 175 \\
\hline 19 & 4 & 0 & 1 & 2 & 18 & 31 & 44 & 57 & 70 & 83 & 96 & 109 & 122 & 135 & 148 & 161 & 174 \\
\hline 20 & 5 & 0 & 1 & 2 & 20 & 33 & 46 & & 72 & 85 & 98 & 111 & 124 & 137 & 150 & 163 & 176 \\
\hline 21 & 6 & 0 & 1 & 2 & 17 & 30 & 43 & & 69 & 82 & 95 & 108 & 121 & 134 & 147 & 160 & 173 \\
\hline 22 & 7 & 0 & 1 & 2 & 26 & 39 & 52 & 65 & 78 & 91 & 104 & 117 & 130 & 143 & 156 & 169 & 182 \\
\hline 23 & 8 & $\mathbf{0}$ & 1 & 2 & 23 & 36 & 49 & 62 & 75 & 88 & 101 & 114 & 127 & 140 & 153 & 166 & 179 \\
\hline 24 & 9 & 0 & 1 & 2 & 25 & 38 & 51 & 64 & 77 & 90 & 103 & 116 & 129 & 142 & 155 & 168 & 181 \\
\hline 25 & 10 & 0 & 1 & 2 & 24 & 37 & 50 & 63 & 76 & 89 & 102 & 115 & 128 & 141 & 154 & 167 & 180 \\
\hline 26 & 11 & 0 & 1 & 2 & 22 & 35 & 48 & 61 & 74 & 87 & 100 & 113 & 126 & 139 & 152 & 165 & 178 \\
\hline 27 & 12 & 0 & 1 & 2 & 16 & 29 & 42 & 55 & 68 & 81 & 94 & 107 & 120 & 133 & 146 & 159 & 172 \\
\hline 28 & $\mathbf{0}$ & 1 & 1 & 1 & 171 & 172 & 173 & 174 & 175 & 176 & 177 & 178 & 179 & 180 & 181 & 182 & 183 \\
\hline 29 & 1 & 1 & 1 & 14 & 27 & 39 & 51 & 63 & 75 & 87 & 99 & 111 & 123 & 135 & 147 & 159 & 171 \\
\hline 30 & 2 & 1 & 1 & 8 & 21 & 40 & 46 & 65 & 71 & 90 & 96 & 115 & 121 & 140 & 146 & 165 & 171 \\
\hline 31 & 3 & 1 & 1 & 6 & 19 & 36 & 53 & 57 & 74 & 91 & 95 & 112 & 129 & 133 & 150 & 167 & 171 \\
\hline 32 & 4 & 1 & 1 & 5 & 18 & 34 & 50 & 66 & 69 & 85 & 101 & 117 & 120 & 136 & 152 & 168 & 171 \\
\hline 33 & 5 & 1 & 1 & 7 & 20 & 38 & 43 & 61 & 79 & 84 & 102 & 107 & 125 & 143 & 148 & 166 & 171 \\
\hline 34 & 6 & 1 & 1 & 4 & 17 & 32 & 47 & 62 & 77 & 92 & 94 & 109 & 124 & 139 & 154 & 169 & 171 \\
\hline 35 & 7 & 1 & 1 & 13 & 26 & 37 & 48 & 59 & 70 & 81 & 105 & 116 & 127 & 138 & 149 & 160 & 171 \\
\hline
\end{tabular}




\begin{tabular}{|c|c|c|c|c|c|c|c|c|c|c|c|c|c|c|c|c|c|}
\hline 36 & 8 & 1 & 1 & 10 & 23 & 31 & 52 & 60 & 68 & 89 & 97 & 118 & 126 & 134 & 155 & 163 & 171 \\
\hline 37 & 9 & 1 & 1 & 12 & 25 & 35 & 45 & 55 & 78 & 88 & 98 & 108 & 131 & 141 & 151 & 161 & 171 \\
\hline 38 & 10 & 1 & 1 & 11 & 24 & 33 & 42 & 64 & 73 & 82 & 104 & 113 & 122 & 144 & 153 & 162 & 171 \\
\hline 39 & 11 & 1 & 1 & 9 & 22 & 29 & 49 & 56 & 76 & 83 & 103 & 110 & 130 & 137 & 157 & 164 & 171 \\
\hline 40 & 12 & 1 & 1 & 3 & 16 & 30 & 44 & 58 & 72 & 86 & 100 & 114 & 128 & 142 & 156 & 170 & 171 \\
\hline 41 & 0 & 2 & 1 & 1 & 93 & 94 & 95 & 96 & 97 & 98 & 99 & 100 & 101 & 102 & 103 & 104 & 105 \\
\hline 42 & 1 & 2 & 1 & 13 & 27 & 38 & 49 & 60 & 71 & 82 & 93 & 117 & 128 & 139 & 150 & 161 & 172 \\
\hline 43 & 2 & 2 & 1 & 14 & 21 & 33 & 45 & 57 & 69 & 81 & 93 & 118 & 130 & 142 & 154 & 166 & 178 \\
\hline 44 & 3 & 2 & 1 & 10 & 19 & 40 & 48 & 56 & 77 & 85 & 93 & 114 & 122 & 143 & 151 & 159 & 180 \\
\hline 45 & 4 & 2 & 1 & 8 & 18 & 37 & 43 & 62 & 68 & 87 & 93 & 112 & 131 & 137 & 156 & 162 & 181 \\
\hline 46 & 5 & 2 & 1 & 12 & 20 & 30 & 53 & 63 & 73 & 83 & 93 & 116 & 126 & 136 & 146 & 169 & 179 \\
\hline 47 & 6 & 2 & 1 & 6 & 17 & 34 & 51 & 55 & 72 & 89 & 93 & 110 & 127 & 144 & 148 & 165 & 182 \\
\hline 48 & 7 & 2 & 1 & 11 & 26 & 35 & 44 & 66 & 75 & 84 & 93 & 115 & 124 & 133 & 155 & 164 & 173 \\
\hline 49 & 8 & 2 & 1 & 5 & 23 & 39 & 42 & 58 & 74 & 90 & 93 & 109 & 125 & 141 & 157 & 160 & 176 \\
\hline 50 & 9 & 2 & 1 & 9 & 25 & 32 & 52 & 59 & 79 & 86 & 93 & 113 & 120 & 140 & 147 & 167 & 174 \\
\hline 51 & 10 & 2 & 1 & 7 & 24 & 29 & 47 & 65 & 70 & 88 & 93 & 111 & 129 & 134 & 152 & 170 & 175 \\
\hline 52 & 11 & 2 & 1 & 3 & 22 & 36 & 50 & 64 & 78 & 92 & 93 & 107 & 121 & 135 & 149 & 163 & 177 \\
\hline 53 & 12 & 2 & 1 & 4 & 16 & 31 & 46 & 61 & 76 & 91 & 93 & 108 & 123 & 138 & 153 & 168 & 183 \\
\hline 54 & 0 & 3 & 1 & 1 & 67 & 68 & 69 & 70 & 71 & 72 & 73 & 74 & 75 & 76 & 77 & 78 & 79 \\
\hline 55 & 1 & 3 & 1 & 12 & 27 & 37 & 47 & 57 & 67 & 90 & 100 & 110 & 120 & 143 & 153 & 163 & 173 \\
\hline 56 & 2 & 3 & 1 & 7 & 21 & 39 & 44 & 62 & 67 & 85 & 103 & 108 & 126 & 144 & 149 & 167 & 172 \\
\hline 57 & 3 & 3 & 1 & 14 & 19 & 31 & 43 & 55 & 67 & 92 & 104 & 116 & 128 & 140 & 152 & 164 & 176 \\
\hline 58 & 4 & 3 & 1 & 11 & 18 & 40 & 49 & 58 & 67 & 89 & 98 & 107 & 129 & 138 & 147 & 169 & 178 \\
\hline 59 & 5 & 3 & 1 & 4 & 20 & 35 & 50 & 65 & 67 & 82 & 97 & 112 & 127 & 142 & 157 & 159 & 174 \\
\hline 60 & 6 & 3 & 1 & 8 & 17 & 36 & 42 & 61 & 67 & 86 & 105 & 111 & 130 & 136 & 155 & 161 & 180 \\
\hline 61 & 7 & 3 & 1 & 9 & 26 & 33 & 53 & 60 & 67 & 87 & 94 & 114 & 121 & 141 & 148 & 168 & 175 \\
\hline 62 & 8 & 3 & 1 & 13 & 23 & 34 & 45 & 56 & 67 & 91 & 102 & 113 & 124 & 135 & 146 & 170 & 181 \\
\hline 63 & 9 & 3 & 1 & 6 & 25 & 29 & 46 & 63 & 67 & 84 & 101 & 118 & 122 & 139 & 156 & 160 & 177 \\
\hline 64 & 10 & 3 & 1 & 3 & 24 & 38 & 52 & 66 & 67 & 81 & 95 & 109 & 123 & 137 & 151 & 165 & 179 \\
\hline 65 & 11 & 3 & 1 & 10 & 22 & 30 & 51 & 59 & 67 & 88 & 96 & 117 & 125 & 133 & 154 & 162 & 183 \\
\hline 66 & 12 & 3 & 1 & 5 & 16 & 32 & 48 & 64 & 67 & 83 & 99 & 115 & 131 & 134 & 150 & 166 & 182 \\
\hline 67 & 0 & 4 & 1 & 1 & 54 & 55 & 56 & 57 & 58 & 59 & 60 & 61 & 62 & 63 & 64 & 65 & 66 \\
\hline 68 & 1 & 4 & 1 & 11 & 27 & 36 & 45 & 54 & 76 & 85 & 94 & 116 & 125 & 134 & 156 & 165 & 174 \\
\hline 69 & 2 & 4 & 1 & 13 & 21 & 32 & 43 & 54 & 78 & 89 & 100 & 111 & 122 & 133 & 157 & 168 & 179 \\
\hline 70 & 3 & 4 & 1 & 5 & 19 & 35 & 51 & 54 & 70 & 86 & 102 & 118 & 121 & 137 & 153 & 169 & 172 \\
\hline 71 & 4 & 4 & 1 & 14 & 18 & 30 & 42 & 54 & 79 & 91 & 103 & 115 & 127 & 139 & 151 & 163 & 175 \\
\hline 72 & 5 & 4 & 1 & 9 & 20 & 40 & 47 & 54 & 74 & 81 & 101 & 108 & 128 & 135 & 155 & 162 & 182 \\
\hline 73 & 6 & 4 & 1 & 10 & 17 & 38 & 46 & 54 & 75 & 83 & 104 & 112 & 120 & 141 & 149 & 170 & 178 \\
\hline 74 & 7 & 4 & 1 & 7 & 26 & 31 & 49 & 54 & 72 & 90 & 95 & 113 & 131 & 136 & 154 & 159 & 177 \\
\hline
\end{tabular}




\begin{tabular}{|c|c|c|c|c|c|c|c|c|c|c|c|c|c|c|c|c|c|}
\hline 75 & 8 & 4 & 1 & 8 & 23 & 29 & 48 & 54 & 73 & 92 & 98 & 117 & 123 & 142 & 148 & 167 & 173 \\
\hline 76 & 9 & 4 & 1 & 3 & 25 & 39 & 53 & 54 & 68 & 82 & 96 & 110 & 124 & 138 & 152 & 166 & 180 \\
\hline 77 & 10 & 4 & 1 & 12 & 24 & 34 & 44 & 54 & 77 & 87 & 97 & 107 & 130 & 140 & 150 & 160 & 183 \\
\hline 78 & 11 & 4 & 1 & 4 & 22 & 37 & 52 & 54 & 69 & 84 & 99 & 114 & 129 & 144 & 146 & 161 & 176 \\
\hline 79 & 12 & 4 & 1 & 6 & 16 & 33 & 50 & 54 & 71 & 88 & 105 & 109 & 126 & 143 & 147 & 164 & 181 \\
\hline 80 & 0 & 5 & 1 & 1 & 80 & 81 & 82 & 83 & 84 & 85 & 86 & 87 & 88 & 89 & 90 & 91 & 92 \\
\hline 81 & 1 & 5 & 1 & 10 & 27 & 35 & 43 & 64 & 72 & 80 & 101 & 109 & 130 & 138 & 146 & 167 & 175 \\
\hline 82 & 2 & 5 & 1 & 6 & 21 & 38 & 42 & 59 & 76 & 80 & 97 & 114 & 131 & 135 & 152 & 169 & 173 \\
\hline 83 & 3 & 5 & 1 & 9 & 19 & 39 & 46 & 66 & 73 & 80 & 100 & 107 & 127 & 134 & 154 & 161 & 181 \\
\hline 84 & 4 & 5 & 1 & 4 & 18 & 33 & 48 & 63 & 78 & 80 & 95 & 110 & 125 & 140 & 155 & 170 & 172 \\
\hline 85 & 5 & 5 & 1 & 14 & 20 & 32 & 44 & 56 & 68 & 80 & 105 & 117 & 129 & 141 & 153 & 165 & 177 \\
\hline 86 & 6 & 5 & 1 & 12 & 17 & 40 & 50 & 60 & 70 & 80 & 103 & 113 & 123 & 133 & 156 & 166 & 176 \\
\hline 87 & 7 & 5 & 1 & 5 & 26 & 29 & 45 & 61 & 77 & 80 & 96 & 112 & 128 & 144 & 147 & 163 & 179 \\
\hline 88 & 8 & 5 & 1 & 3 & 23 & 37 & 51 & 65 & 79 & 80 & 94 & 108 & 122 & 136 & 150 & 164 & 178 \\
\hline 89 & 9 & 5 & 1 & 13 & 25 & 36 & 47 & 58 & 69 & 80 & 104 & 115 & 126 & 137 & 148 & 159 & 183 \\
\hline 90 & 10 & 5 & 1 & 8 & 24 & 30 & 49 & 55 & 74 & 80 & 99 & 118 & 124 & 143 & 149 & 168 & 174 \\
\hline 91 & 11 & 5 & 1 & 11 & 22 & 31 & 53 & 62 & 71 & 80 & 102 & 111 & 120 & 142 & 151 & 160 & 182 \\
\hline 92 & 12 & 5 & 1 & 7 & 16 & 34 & 52 & 57 & 75 & 80 & 98 & 116 & 121 & 139 & 157 & 162 & 180 \\
\hline 93 & 0 & 6 & 1 & 1 & 41 & 42 & 43 & 44 & 45 & 46 & 47 & 48 & 49 & 50 & 51 & 52 & 53 \\
\hline 94 & 1 & 6 & 1 & 9 & 27 & 34 & 41 & 61 & 68 & 88 & 95 & 115 & 122 & 142 & 149 & 169 & 176 \\
\hline 95 & 2 & 6 & 1 & 12 & 21 & 31 & 41 & 64 & 74 & 84 & 94 & 117 & 127 & 137 & 147 & 170 & 180 \\
\hline 96 & 3 & 6 & 1 & 13 & 19 & 30 & 41 & 65 & 76 & 87 & 98 & 109 & 120 & 144 & 155 & 166 & 177 \\
\hline 97 & 4 & 6 & 1 & 7 & 18 & 36 & 41 & 59 & 77 & 82 & 100 & 118 & 123 & 141 & 146 & 164 & 182 \\
\hline 98 & 5 & 6 & 1 & 6 & 20 & 37 & 41 & 58 & 75 & 92 & 96 & 113 & 130 & 134 & 151 & 168 & 172 \\
\hline 99 & 6 & 6 & 1 & 14 & 17 & 29 & 41 & 66 & 78 & 90 & 102 & 114 & 126 & 138 & 150 & 162 & 174 \\
\hline 100 & 7 & 6 & 1 & 3 & 26 & 40 & 41 & 55 & 69 & 83 & 97 & 111 & 125 & 139 & 153 & 167 & 181 \\
\hline 101 & 8 & 6 & 1 & 11 & 23 & 32 & 41 & 63 & 72 & 81 & 103 & 112 & 121 & 143 & 152 & 161 & 183 \\
\hline 102 & 9 & 6 & 1 & 10 & 25 & 33 & 41 & 62 & 70 & 91 & 99 & 107 & 128 & 136 & 157 & 165 & 173 \\
\hline 103 & 10 & 6 & 1 & 4 & 24 & 39 & 41 & 56 & 71 & 86 & 101 & 116 & 131 & 133 & 148 & 163 & 178 \\
\hline 104 & 11 & 6 & 1 & 5 & 22 & 38 & 41 & 57 & 73 & 89 & 105 & 108 & 124 & 140 & 156 & 159 & 175 \\
\hline 105 & 12 & 6 & 1 & 8 & 16 & 35 & 41 & 60 & 79 & 85 & 104 & 110 & 129 & 135 & 154 & 160 & 179 \\
\hline 106 & $\mathbf{0}$ & 7 & 1 & 1 & 158 & 159 & 160 & 161 & 162 & 163 & 164 & 165 & 166 & 167 & 168 & 169 & 170 \\
\hline 107 & 1 & 7 & 1 & 8 & 27 & 33 & 52 & 58 & 77 & 83 & 102 & 108 & 127 & 133 & 152 & 158 & 177 \\
\hline 108 & 2 & 7 & 1 & 5 & 21 & 37 & 53 & 56 & 72 & 88 & 104 & 107 & 123 & 139 & 155 & 158 & 174 \\
\hline 109 & 3 & 7 & 1 & 4 & 19 & 34 & 49 & 64 & 79 & 81 & 96 & 111 & 126 & 141 & 156 & 158 & 173 \\
\hline 110 & 4 & 7 & 1 & 10 & 18 & 39 & 47 & 55 & 76 & 84 & 105 & 113 & 121 & 142 & 150 & 158 & 179 \\
\hline 111 & 5 & 7 & 1 & 11 & 20 & 29 & 51 & 60 & 69 & 91 & 100 & 109 & 131 & 140 & 149 & 158 & 180 \\
\hline 112 & 6 & 7 & 1 & 3 & 17 & 31 & 45 & 59 & 73 & 87 & 101 & 115 & 129 & 143 & 157 & 158 & 172 \\
\hline 113 & 7 & 7 & 1 & 14 & 26 & 38 & 50 & 62 & 74 & 86 & 98 & 110 & 122 & 134 & 146 & 158 & 183 \\
\hline
\end{tabular}




\begin{tabular}{|c|c|c|c|c|c|c|c|c|c|c|c|c|c|c|c|c|c|}
\hline 114 & 8 & 7 & 1 & 6 & 23 & 40 & 44 & 61 & 78 & 82 & 99 & 116 & 120 & 137 & 154 & 158 & 175 \\
\hline 115 & 9 & 7 & 1 & 7 & 25 & 30 & 48 & 66 & 71 & 89 & 94 & 112 & 130 & 135 & 153 & 158 & 176 \\
\hline 116 & 10 & 7 & 1 & 13 & 24 & 35 & 46 & 57 & 68 & 92 & 103 & 114 & 125 & 136 & 147 & 158 & 182 \\
\hline 117 & 11 & 7 & 1 & 12 & 22 & 32 & 42 & 65 & 75 & 85 & 95 & 118 & 128 & 138 & 148 & 158 & 181 \\
\hline 118 & 12 & 7 & 1 & 9 & 16 & 36 & 43 & 63 & 70 & 90 & 97 & 117 & 124 & 144 & 151 & 158 & 178 \\
\hline 119 & 0 & 8 & 1 & 1 & 119 & 120 & 121 & 122 & 123 & 124 & 125 & 126 & 127 & 128 & 129 & 130 & 131 \\
\hline 120 & 1 & 8 & 1 & 7 & 27 & 32 & 50 & 55 & 73 & 91 & 96 & 114 & 119 & 137 & 155 & 160 & 178 \\
\hline 121 & 2 & 8 & 1 & 11 & 21 & 30 & 52 & 61 & 70 & 92 & 101 & 110 & 119 & 141 & 150 & 159 & 181 \\
\hline 122 & 3 & 8 & 1 & 8 & 19 & 38 & 44 & 63 & 69 & 88 & 94 & 113 & 119 & 138 & 157 & 163 & 182 \\
\hline 123 & 4 & 8 & 1 & 13 & 18 & 29 & 53 & 64 & 75 & 86 & 97 & 108 & 119 & 143 & 154 & 165 & 176 \\
\hline 124 & 5 & 8 & 1 & 3 & 20 & 34 & 48 & 62 & 76 & 90 & 104 & 118 & 119 & 133 & 147 & 161 & 175 \\
\hline 125 & 6 & 8 & 1 & 5 & 17 & 33 & 49 & 65 & 68 & 84 & 100 & 116 & 119 & 135 & 151 & 167 & 183 \\
\hline 126 & 7 & 8 & 1 & 12 & 26 & 36 & 46 & 56 & 79 & 89 & 99 & 109 & 119 & 142 & 152 & 162 & 172 \\
\hline 127 & 8 & 8 & 1 & 14 & 23 & 35 & 47 & 59 & 71 & 83 & 95 & 107 & 119 & 144 & 156 & 168 & 180 \\
\hline 128 & 9 & 8 & 1 & 4 & 25 & 40 & 42 & 57 & 72 & 87 & 102 & 117 & 119 & 134 & 149 & 164 & 179 \\
\hline 129 & 10 & 8 & 1 & 9 & 24 & 31 & 51 & 58 & 78 & 85 & 105 & 112 & 119 & 139 & 146 & 166 & 173 \\
\hline 130 & 11 & 8 & 1 & 6 & 22 & 39 & 43 & 60 & 77 & 81 & 98 & 115 & 119 & 136 & 153 & 170 & 174 \\
\hline 131 & 12 & 8 & 1 & 10 & 16 & 37 & 45 & 66 & 74 & 82 & 103 & 111 & 119 & 140 & 148 & 169 & 177 \\
\hline 132 & 0 & 9 & 1 & 1 & 145 & 146 & 147 & 148 & 149 & 150 & 151 & 152 & 153 & 154 & 155 & 156 & 157 \\
\hline 133 & 1 & 9 & 1 & 6 & 27 & 31 & 48 & 65 & 69 & 86 & 103 & 107 & 124 & 141 & 145 & 162 & 179 \\
\hline 134 & 2 & 9 & 1 & 4 & 21 & 36 & 51 & 66 & 68 & 83 & 98 & 113 & 128 & 143 & 145 & 160 & 175 \\
\hline 135 & 3 & 9 & 1 & 12 & 19 & 29 & 52 & 62 & 72 & 82 & 105 & 115 & 125 & 135 & 145 & 168 & 178 \\
\hline 136 & 4 & 9 & 1 & 3 & 18 & 32 & 46 & 60 & 74 & 88 & 102 & 116 & 130 & 144 & 145 & 159 & 173 \\
\hline 137 & 5 & 9 & 1 & 8 & 20 & 39 & 45 & 64 & 70 & 89 & 95 & 114 & 120 & 139 & 145 & 164 & 183 \\
\hline 138 & 6 & 9 & 1 & 7 & 17 & 35 & 53 & 58 & 76 & 81 & 99 & 117 & 122 & 140 & 145 & 163 & 181 \\
\hline 139 & 7 & 9 & 1 & 10 & 26 & 34 & 42 & 63 & 71 & 92 & 100 & 108 & 129 & 137 & 145 & 166 & 174 \\
\hline 140 & 8 & 9 & 1 & 9 & 23 & 30 & 50 & 57 & 77 & 84 & 104 & 111 & 131 & 138 & 145 & 165 & 172 \\
\hline 141 & 9 & 9 & 1 & 14 & 25 & 37 & 49 & 61 & 73 & 85 & 97 & 109 & 121 & 133 & 145 & 170 & 182 \\
\hline 142 & 10 & 9 & 1 & 5 & 24 & 40 & 43 & 59 & 75 & 91 & 94 & 110 & 126 & 142 & 145 & 161 & 177 \\
\hline 143 & 11 & 9 & 1 & 13 & 22 & 33 & 44 & 55 & 79 & 90 & 101 & 112 & 123 & 134 & 145 & 169 & 180 \\
\hline 144 & 12 & 9 & 1 & 11 & 16 & 38 & 47 & 56 & 78 & 87 & 96 & 118 & 127 & 136 & 145 & 167 & 176 \\
\hline 145 & 0 & 10 & 1 & 1 & 132 & 133 & 134 & 135 & 136 & 137 & 138 & 139 & 140 & 141 & 142 & 143 & 144 \\
\hline 146 & 1 & 10 & 1 & 5 & 27 & 30 & 46 & 62 & 78 & 81 & 97 & 113 & 129 & 132 & 148 & 164 & 180 \\
\hline 147 & 2 & 10 & 1 & 10 & 21 & 29 & 50 & 58 & 79 & 87 & 95 & 116 & 124 & 132 & 153 & 161 & 182 \\
\hline 148 & 3 & 10 & 1 & 3 & 19 & 33 & 47 & 61 & 75 & 89 & 103 & 117 & 131 & 132 & 146 & 160 & 174 \\
\hline 149 & 4 & 10 & 1 & 6 & 18 & 35 & 52 & 56 & 73 & 90 & 94 & 111 & 128 & 132 & 149 & 166 & 183 \\
\hline 150 & 5 & 10 & 1 & 13 & 20 & 31 & 42 & 66 & 77 & 88 & 99 & 110 & 121 & 132 & 156 & 167 & 178 \\
\hline 151 & 6 & 10 & 1 & 9 & 17 & 37 & 44 & 64 & 71 & 91 & 98 & 118 & 125 & 132 & 152 & 159 & 179 \\
\hline 152 & 7 & 10 & 1 & 8 & 26 & 32 & 51 & 57 & 76 & 82 & 101 & 107 & 126 & 132 & 151 & 170 & 176 \\
\hline
\end{tabular}




\begin{tabular}{|c|c|c|c|c|c|c|c|c|c|c|c|c|c|c|c|c|c|}
\hline 153 & 8 & 10 & 1 & 4 & 23 & 38 & 53 & 55 & 70 & 85 & 100 & 115 & 130 & 132 & 147 & 162 & 177 \\
\hline 154 & 9 & 10 & 1 & 11 & 25 & 34 & 43 & 65 & 74 & 83 & 105 & 114 & 123 & 132 & 154 & 163 & 172 \\
\hline 155 & 10 & 10 & 1 & 14 & 24 & 36 & 48 & 60 & 72 & 84 & 96 & 108 & 120 & 132 & 157 & 169 & 181 \\
\hline 156 & 11 & 10 & 1 & 7 & 22 & 40 & 45 & 63 & 68 & 86 & 104 & 109 & 127 & 132 & 150 & 168 & 173 \\
\hline 157 & 12 & 10 & 1 & 12 & 16 & 39 & 49 & 59 & 69 & 92 & 102 & 112 & 122 & 132 & 155 & 165 & 175 \\
\hline 158 & 0 & 11 & 1 & 1 & 106 & 107 & 108 & 109 & 110 & 111 & 112 & 113 & 114 & 115 & 116 & 117 & 118 \\
\hline 159 & 1 & 11 & 1 & 4 & 27 & 29 & 44 & 59 & 74 & 89 & 104 & 106 & 121 & 136 & 151 & 166 & 181 \\
\hline 160 & 2 & 11 & 1 & 3 & 21 & 35 & 49 & 63 & 77 & 91 & 105 & 106 & 120 & 134 & 148 & 162 & 176 \\
\hline 161 & 3 & 11 & 1 & 7 & 19 & 37 & 42 & 60 & 78 & 83 & 101 & 106 & 124 & 142 & 147 & 165 & 183 \\
\hline 162 & 4 & 11 & 1 & 9 & 18 & 38 & 45 & 65 & 72 & 92 & 99 & 106 & 126 & 133 & 153 & 160 & 180 \\
\hline 163 & 5 & 11 & 1 & 5 & 20 & 36 & 52 & 55 & 71 & 87 & 103 & 106 & 122 & 138 & 154 & 170 & 173 \\
\hline 164 & 6 & 11 & 1 & 11 & 17 & 39 & 48 & 57 & 79 & 88 & 97 & 106 & 128 & 137 & 146 & 168 & 177 \\
\hline 165 & 7 & 11 & 1 & 6 & 26 & 30 & 47 & 64 & 68 & 85 & 102 & 106 & 123 & 140 & 157 & 161 & 178 \\
\hline 166 & 8 & 11 & 1 & 12 & 23 & 33 & 43 & 66 & 76 & 86 & 96 & 106 & 129 & 139 & 149 & 159 & 182 \\
\hline 167 & 9 & 11 & 1 & 8 & 25 & 31 & 50 & 56 & 75 & 81 & 100 & 106 & 125 & 144 & 150 & 169 & 175 \\
\hline 168 & 10 & 11 & 1 & 10 & 24 & 32 & 53 & 61 & 69 & 90 & 98 & 106 & 127 & 135 & 156 & 164 & 172 \\
\hline 169 & 11 & 11 & 1 & 14 & 22 & 34 & 46 & 58 & 70 & 82 & 94 & 106 & 131 & 143 & 155 & 167 & 179 \\
\hline 170 & 12 & 11 & 1 & 13 & 16 & 40 & 51 & 62 & 73 & 84 & 95 & 106 & 130 & 141 & 152 & 163 & 174 \\
\hline 171 & 0 & 12 & 1 & 1 & 28 & 29 & 30 & 31 & 32 & 33 & 34 & 35 & 36 & 37 & 38 & 39 & 40 \\
\hline 172 & 1 & 12 & 1 & 3 & 27 & 28 & 42 & 56 & 70 & 84 & 98 & 112 & 126 & 140 & 154 & 168 & 182 \\
\hline 173 & 2 & 12 & 1 & 9 & 21 & 28 & 48 & 55 & 75 & 82 & 102 & 109 & 129 & 136 & 156 & 163 & 183 \\
\hline 174 & 3 & 12 & 1 & 11 & 19 & 28 & 50 & 59 & 68 & 90 & 99 & 108 & 130 & 139 & 148 & 170 & 179 \\
\hline 175 & 4 & 12 & 1 & 12 & 18 & 28 & 51 & 61 & 71 & 81 & 104 & 114 & 124 & 134 & 157 & 167 & 177 \\
\hline 176 & 5 & 12 & 1 & 10 & 20 & 28 & 49 & 57 & 78 & 86 & 94 & 115 & 123 & 144 & 152 & 160 & 181 \\
\hline 177 & 6 & 12 & 1 & 13 & 17 & 28 & 52 & 63 & 74 & 85 & 96 & 107 & 131 & 142 & 153 & 164 & 175 \\
\hline 178 & 7 & 12 & 1 & 4 & 26 & 28 & 43 & 58 & 73 & 88 & 103 & 118 & 120 & 135 & 150 & 165 & 180 \\
\hline 179 & 8 & 12 & 1 & 7 & 23 & 28 & 46 & 64 & 69 & 87 & 105 & 110 & 128 & 133 & 151 & 169 & 174 \\
\hline 180 & 9 & 12 & 1 & 5 & 25 & 28 & 44 & 60 & 76 & 92 & 95 & 111 & 127 & 143 & 146 & 162 & 178 \\
\hline 181 & 10 & 12 & 1 & 6 & 24 & 28 & 45 & 62 & 79 & 83 & 100 & 117 & 121 & 138 & 155 & 159 & 176 \\
\hline 182 & 11 & 12 & 1 & 8 & 22 & 28 & 47 & 66 & 72 & 91 & 97 & 116 & 122 & 141 & 147 & 166 & 172 \\
\hline 183 & 12 & 12 & 1 & 14 & 16 & 28 & 53 & 65 & 77 & 89 & 101 & 113 & 125 & 137 & 149 & 161 & 173 \\
\hline
\end{tabular}

